OESOPHAGUS

\title{
Nitrate and nitrosative chemistry within Barrett's oesophagus during acid reflux
}

\author{
H Suzuki, K lijima, G Scobie, V Fyfe, K E L McColl
}

Gut 2005;54:1527-1535. doi: 10.1136/gut.2005.066043

Background and aims: When saliva, with its high nitrite content derived from the enterosalivary recirculation of dietary nitrate, meets acidic gastric juice, the nitrite is converted to nitrous acid, nitrosative species, and nitric oxide. In healthy volunteers this potentially mutagenic chemistry is focused at the gastric cardia. We have studied the location of this luminal chemistry in Barrett's patients during acid reflux.

See end of article for authors' affiliations Methods: Ten Barrett's patients were studied before and after administration of $2 \mathrm{mmol}$ nitrate. Using microdialysis probes we measured nitrite, ascorbic acid, total vitamin C, and thiocyanate concentrations and $\mathrm{pH}$ simultaneously in the proximal oesophagus, Barrett's segment, hiatal sac, proximal stomach, and distal stomach. In a subgroup, real time nitric oxide concentrations were also measured.

Correspondence to: Professor K E L McColl, Section of Medicine, Western Infirmary, 44 Church St, Glasgow G1 1 6NT, UK; K.E.L.McColl@ clinmed.gla.ac.uk

Results: During acid reflux, Barrett's segment was the anatomical site with maximal potential for acid catalysed nitrosation, with its median concentration of nitrite exceeding that of ascorbic acid in two of 10 subjects before nitrate and in four of nine after nitrate. Thiocyanate, which catalyses acid nitrosation, was abundant at all anatomical sites. On entering the acidic Barrett's segment, there was a substantial fall in nitrite and the lowest ascorbic acid to total vitamin $C$ ratio, indicative of reduction of salivary nitrite to nitric

Revised version received 2 June 2005 Accepted for publication 10 June 2005 oxide at this anatomical site. Episodes of acid reflux were observed to generate nitric oxide concentrations of up to $60 \mu \mathrm{M}$ within the Barrett's segment.

Conclusion: The interaction between acidic gastric refluxate and nitrite rich saliva activates potentially mutagenic luminal nitrosative chemistry within Barrett's oesophagus.

$\mathrm{T}$ he incidence of adenocarcinoma of the oesophagus has increased markedly over the past 25 years. ${ }^{12}$ An important risk factor for this cancer is gastro-oesophageal reflux. ${ }^{3}$ It is assumed that reflux of gastric acid, pepsin, and possibly bile causes progressive damage to the oesophageal mucosa leading to columnar and intestinal metaplasia, dysplasia, and adenocarcinoma. However, it is unclear whether the mucosal damage induced by the refluxate is sufficient to induce cancer or whether it merely sensitises the epithelium to luminal carcinogens.

For many years, there has been interest in luminal nitrite as a potential precarcinogen of the human upper gastrointestinal tract. The main source of nitrite in the upper gastrointestinal tract is swallowed saliva and its high nitrite content is derived from dietary nitrate. Twenty five per cent of the nitrate absorbed into the body is taken up from the circulation by the salivary glands and secreted into the mouth. ${ }^{4}$ Bacteria which colonise the dorsum of the tongue convert approximately $30 \%$ of the nitrate to nitrite. ${ }^{56}$ Approximately $1500 \mathrm{ml}$ of saliva are swallowed every 24 hours, with a nitrite concentration varying between $20 \mu \mathrm{mol} / \mathrm{l}$ and $5 \mathrm{mmol} / \mathrm{l}^{57}$ Large amounts of nitrite are thus delivered into the human oesophagus and stomach in swallowed saliva.

When nitrite in swallowed, saliva passes from the neutral $\mathrm{pH}$ of the oesophageal lumen into the acidic environment of the gastric lumen where it is immediately converted to nitrous acid and nitrosating species such as $\mathrm{N}_{2} \mathrm{O}_{3}$ and $\mathrm{NO}^{+} .89$ The latter species combines with the thiocyanate anion, which is also secreted in saliva, to form the important nitrosating species NOSCN. ${ }^{8}{ }^{9}$ These nitrosating species can react with a variety of $N$-nitrosatable compounds to form potentially carcinogenic $N$-nitroso compounds. ${ }^{89}$

The main factor inhibiting the generation of $N$-nitroso compounds from nitrite entering the acidic stomach is ascorbic acid which is actively secreted in gastric juice. ${ }^{10}{ }^{11}$ The vitamin reacts with the nitrosating species, reducing

them to nitric oxide, and in the process is itself oxidised to dehydroascorbic acid. ${ }^{12-14}$ Although this action of ascorbic acid inhibits the luminal generation of $N$-nitroso compounds, the nitric oxide produced in the process can readily diffuse into the adjacent epithelium and within it induce nitrosative stress. ${ }^{14}$ This arises from the fact that nitric oxide, when present in high concentrations, rapidly reacts with molecular oxygen to form the nitrosating species $\mathrm{N}_{2} \mathrm{O}_{3} \cdot{ }^{15}$ The latter can directly deaminate DNA or indirectly damage DNA via the formation of $\mathrm{N}$-nitroso compounds. ${ }^{15} \mathrm{Nitric}$ oxide has also been shown to inhibit a number of DNA repair enzymes. ${ }^{16}{ }^{17}$

We recently examined luminal nitrite chemistry following nitrate ingestion in subjects with healthy acid secreting stomachs and without reflux disease. ${ }^{18}$ We found that this chemistry was focused at the gastric cardia where nitrite in saliva first encounters acidic gastric juice. This anatomical location had the chemical conditions most favouring luminal $\mathrm{N}$-nitroso compound formation in being the acidic environment with the highest nitrite and lowest vitamin C concentration. In addition, we found that the peak nitric oxide concentration generated from dietary nitrate occurred at the gastric cardia. ${ }^{19}$ These observations raise the possibility that the active luminal nitrosating chemistry occurring at the gastric cardia may contribute to the high incidence of mutagenesis occurring at this anatomical site.

In subjects with severe gastro-oesophageal reflux, the anatomical location where saliva first encounters acidic gastric juice is moved proximally, occurring within the oesophagus rather than at the gastric cardia. In the present study, we have examined luminal nitrite chemistry following nitrate ingestion in patients with severe gastro-oesophageal reflux disease. Our investigations indicate that gastrooesophageal reflux moves the location of maximal luminal nitrosative stress from the gastric cardia into the distal oesophagus. Hence our aim was to study the anatomical location of luminal nitrosative stress arising from salivary nitrite during gastro-oesophageal reflux. 


\section{SUBJECTS AND METHODS}

\section{Subjects}

Patients with endoscopic evidence of Barrett's oesophagus were examined. In each subject, the columnar lined oesophagus extended at least $3 \mathrm{~cm}$ proximal to the upper border of the gastric folds, as determined by previous endoscopy. The size of the hiatal hernia was measured from the proximal gastric fold to the point at which the diaphragmatic constriction of the gastric lumen occurred. Biopsies of the columnar lined oesophagus confirmed intestinal metaplasia in all patients. Each patient was confirmed to be Helicobacter pylori negative by histological examination and rapid urease test of both gastric antral and body mucosal biopsies.

\section{Studies employing microdialysis probes Microdialysis probes}

We used CMA flexible microdialysis probes (MAB 7.8.10; Biotech Instruments Ltd., Herts, UK) to measure local luminal concentrations of the chemicals relevant to nitrosation (that is, nitrite, thiocyanate, ascorbic acid, and total vitamin $\mathrm{C}$ ). We have previously validated this method of studying those chemicals under conditions existing in the human upper gastrointestinal tract. ${ }^{20}$ Five such probes were attached to a $3.3 \mathrm{~mm}$ diameter nasogastric tube (Rüsch Manufacturing, Lurgen, UK), as previously described..$^{18}$ The equipment was individually designed for each patient so that one of the probes would be at each of the following anatomical sites: squamous oesophagus, Barrett's segment, hiatus hernia, proximal stomach, and distal stomach. A multi channel pH catheter (Synectics Medical Ltd., Enfield, UK) was mounted alongside the nasogastric tube so that we could monitor luminal $\mathrm{pH}$ at the site of each microdialysis probe. The hiatal hernia microdialysis probe was positioned $1 \mathrm{~cm}$ below the gastro-oesophageal junction (defined by the position of the proximal gastric fold) and the Barrett's probe $2.5 \mathrm{~cm}$ above the gastro-oesophageal junction. The gastric microdialysis probes were positioned 5 and $10 \mathrm{~cm}$ distal to the hiatal hernia probe. The probe in the squamous oesophagus was positioned $10 \mathrm{~cm}$ proximal to the Barrett's probe. A fine bore Teflon tube (Nutricia Health Care, Trowbridge, Wiltshire, UK) was attached to the assembly with its opening at the tip of the nasogastric tube for intragastric delivery of the nitrate solution.

\section{Clinical procedure using microdialysis probes}

Subjects stopped all antisecretory medications for at least five days and were instructed to avoid nitrate rich foods for 24 hours prior to the procedure. They attended in the morning having fasted since the previous evening and underwent an endoscopic examination to confirm anatomical locations and to apply radio-opaque clips (Hemoclips, Olympus Clips HX-600-090; KeyMed, Southend-on-Sea, UK) at the squamocolumnar junction and the gastrooesophageal junction to delineate Barrett's segment. Following this the microdialysis probe assembly was passed perorally and positioned under fluoroscopy using the clips and $\mathrm{pH}$ sensors as reference points.

The purpose of this study was to examine nitrosation chemistry during gastro-oesophageal reflux. In order to ensure reflux throughout the duration of the experiment, subjects lay in the right lateral decubitus position with or without the head down position to provoke gastro-oesophageal reflux. A low dose of pentagastrin $(0.06 \mu \mathrm{g} / \mathrm{kg} / \mathrm{h})$ (Cambridge Laboratories, Wallsend, UK) was infused intravenously to stimulate physiological levels of gastric secretion and acid reflux.

The first 15 minute collections of the microdialysis samples (representing the dead space in the afferent tubes) were discarded and the following 40 minutes collected for analyses. Following this basal collection, $2 \mathrm{mmol}$ of potassium nitrate were administered intragastrically via the fine Teflon feeding tube attached to the nasogastric tube. This is the amount of nitrate in a portion of salad. ${ }^{21}$ Forty minutes after administering the potassium nitrate, further microdialysis collections were obtained for 40 minutes. This was to ensure that the salivary nitrite concentrations were elevated before commencing the microdialysis collection.

Venous blood was obtained from an indwelling intravenous catheter every 15 minutes for determination of serum nitrate, and samples of saliva were obtained every 15 minutes for nitrite and thiocyanate determination, as previously described. ${ }^{18}$

\section{Studies employing nitric oxide probe \\ Nitric oxide sensor}

We employed a miniaturised custom made nitric oxide sensor (World Precision Instruments Inc., Sarasota, Florida, USA) to allow measurement of luminal nitric oxide concentrations within the upper gastrointestinal tract, as previously described. ${ }^{19}$ An antimony $\mathrm{pH}$ sensor (Synetics Medical Ltd) was attached to the nitric oxide sensor using waterproof taping (Sleek, Smith and Nephew, Hull, UK) with the pH sensor positioned adjacent to the tip of the nitric oxide probe. A fine bore Teflon feeding tube was also attached to the assembly to allow intragastric instillation of the nitrate solution

\section{Clinical procedure using nitric oxide probe}

Three subjects who had taken part in the microdialysis experiment underwent intraoesophageal nitric oxide measurement. The experimental conditions were identical to those for microdialysis experiments. The nitric oxide sensor assembly was inserted orally to a point $10 \mathrm{~cm}$ distal to the gastro-oesophageal junction predetermined endoscopically. A plain abdominal $x$ ray was taken to check the sensor position. The sensor was then withdrawn until it was within Barrett's oesophagus and maintained at a location where intermittent acid reflux was occurring, as indicated by the intermittent fall in $\mathrm{pH}$. Salivary nitrite and serum nitrate were collected every 15 minutes and processed as above.

The sensors were then reinserted to $10 \mathrm{~cm}$ distal to the gastro-oesophageal junction and $2 \mathrm{mmol}$ of potassium nitrate in $50 \mathrm{ml}$ sterile water administered intragastrically. The probe was again withdrawn slowly and maintained in a position within Barrett's segment where there was evidence of intermittent acid reflux.

\section{Chemical analyses}

Concentrations of nitrate, nitrite, ascorbic acid, total vitamin $\mathrm{C}$, and thiocyanate in serum, saliva, and microdialysate were measured as previously described. ${ }^{22-25}$

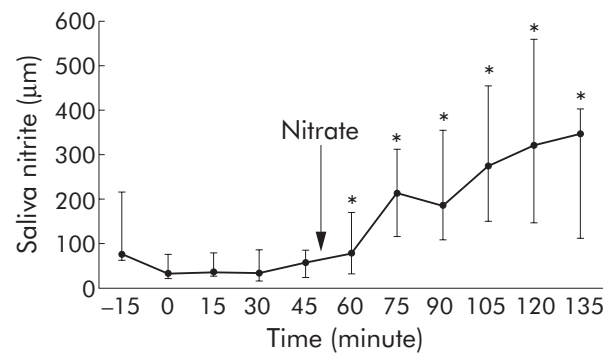

Figure 1 Median salivary nitrite before and after administration of $2 \mathrm{mmol}$ nitrate. The microdialysis assembly was inserted at time 0 minutes. ${ }^{*} p<0.05$ versus 45 minutes (just prior to nitrate administration). 
Table 1 Nitrite, thiocyanate, ascorbic acid, total vitamin C, ascorbic acid (AA)/nitrite ratio, and pH in the different regions of the upper gastrointestinal tract in subjects with Barrett's oesophagus before and after the nitrate meal

\begin{tabular}{|c|c|c|c|c|c|c|c|c|c|c|c|c|}
\hline \multirow[b]{2}{*}{ Site } & \multicolumn{2}{|l|}{$\mathrm{pH}$} & \multicolumn{2}{|l|}{ Nitrite $(\mu M)$} & \multicolumn{2}{|c|}{ Thiocyanate $(\mu \mathrm{M})$} & \multicolumn{2}{|c|}{ Ascorbic acid $(\mu \mathrm{M})$} & \multicolumn{2}{|c|}{ Total vitamin $C(\mu M)$} & \multicolumn{2}{|l|}{$\mathrm{AA} /$ nitrite } \\
\hline & Pre & Post & Preł & Posł & Pre & Post & Preł & Postq & Preł & Post§ & Pre & Post \\
\hline SQO & $\begin{array}{l}6.2^{*} \\
(5.8-7.0)\end{array}$ & $\begin{array}{l}5.7^{*} \\
(4.5-6.5)\end{array}$ & $\begin{array}{l}40.1 \\
(12.7-63.4)\end{array}$ & $\begin{array}{l}106.2 \dagger \\
(75.7-141.6)\end{array}$ & $\begin{array}{l}409 \\
(319-673)\end{array}$ & $\begin{array}{l}390 \\
(202-622)\end{array}$ & $\begin{array}{l}3.5 \\
(0-11.7)\end{array}$ & $\begin{array}{l}1.2 \\
10-12.4\end{array}$ & $\begin{array}{l}3.8 \\
(0-14.7)\end{array}$ & $\begin{array}{l}5.6 \\
(0.4-34.3)\end{array}$ & $\begin{array}{l}0.1 \\
(0.02-0.47)\end{array}$ & $\begin{array}{l}0.02+\dagger \\
(0.01-0.13)\end{array}$ \\
\hline $\mathrm{BO}$ & $\begin{array}{l}2.7^{\star *} \\
(1.6-3.3)\end{array}$ & $\begin{array}{l}2.7^{* *} \\
(1.7-3.8)\end{array}$ & $\begin{array}{l}0 \\
(0-5.9)\end{array}$ & $\begin{array}{l}1.9 \\
(0-7.4)\end{array}$ & $\begin{array}{l}317 \\
(192-511)\end{array}$ & $\begin{array}{l}260 \\
(171-679)\end{array}$ & $\begin{array}{l}9.9 \\
(3.4-16.8)\end{array}$ & $\begin{array}{l}2.9 \\
(0.2-32.4)\end{array}$ & $\begin{array}{l}19.1 \\
(5.1-32.2)\end{array}$ & $\begin{array}{l}23.4 \\
(13.4-28.4)\end{array}$ & $\begin{array}{l}7.4 \\
(1.6-16.8)\end{array}$ & $\begin{array}{l}3.4 \\
(0.14-12.4)\end{array}$ \\
\hline $\mathrm{HH}$ & $\begin{array}{l}1.4 \\
(1.2-1.9)\end{array}$ & $\begin{array}{l}1.6 \\
(1.1-1.9)\end{array}$ & $\begin{array}{l}0 \\
(0-0.3)\end{array}$ & $\begin{array}{l}0 \\
(0-1.1)\end{array}$ & $\begin{array}{l}265 \\
(239-422)\end{array}$ & $\begin{array}{l}235 \\
(207-486)\end{array}$ & $\begin{array}{l}27.7 \\
(6.7-42.5)\end{array}$ & $\begin{array}{l}14.7 \\
(0-42.7)\end{array}$ & $\begin{array}{l}34.1 \\
(10.2-47.5\end{array}$ & $\begin{array}{l}33.4 \\
(21.5-44.9)\end{array}$ & $\begin{array}{l}26.2 \\
(6.7-42.5)\end{array}$ & $\begin{array}{l}29.2 \\
(1.5-47.9)\end{array}$ \\
\hline PS & $\begin{array}{l}1.4 \\
(1.3-1.8)\end{array}$ & $\begin{array}{l}1.5 \\
(1.2-1.6)\end{array}$ & 0 & 0 & $\begin{array}{l}270 \\
(231-434)\end{array}$ & $\begin{array}{l}229 \\
(151-440)\end{array}$ & $\begin{array}{l}38.4 \\
(20.6-66.6)\end{array}$ & $\begin{array}{l}28.4 \\
(9.1-45.4)\end{array}$ & $\begin{array}{l}41.1 \\
(24.9-77.0)\end{array}$ & $\begin{array}{l}35.6 \\
(18.3-71.2)\end{array}$ & $\begin{array}{l}32.3 \\
(15.1-65.2)\end{array}$ & $\begin{array}{l}25.0 \\
(8.5-48.5)\end{array}$ \\
\hline DS & $\begin{array}{l}1.4 \\
(1.2-1.7)\end{array}$ & $\begin{array}{l}1.4 \\
(1.2-1.6)\end{array}$ & 0 & 0 & $\begin{array}{l}279 \\
(223-505)\end{array}$ & $\begin{array}{l}249 \\
(184-494)\end{array}$ & $\begin{array}{l}43.4 \\
(24.1-68.5)\end{array}$ & $\begin{array}{l}48.6 \\
(17.0-73.6)\end{array}$ & $\begin{array}{l}58.9 \\
(22.6-72.8)\end{array}$ & $\begin{array}{l}46.5 \\
(20.0-78.7)\end{array}$ & $\begin{array}{l}32.7 \\
(18.9-68.5)\end{array}$ & $\begin{array}{l}34.2 \\
(13.8-64.3)\end{array}$ \\
\hline
\end{tabular}

Data presented as medians (interquartile range).

$\mathrm{SQO}$, squamous oesophagus; $\mathrm{BO}$, Barrett's oesophagus; $\mathrm{HH}$, hiatus hernia; PS, proximal stomach; DS, distal stomach.

${ }^{*} p<0.05$ versus all other sites; ${ }^{* *} p<0.05$ versus hiatal hernia, proximal stomach, and distal stomach; $\uparrow p=0.03$ versus pre-nitrate; $\dagger+p=0.032$ versus $S Q O$ pre-nitrate; $\neq p<0.001$;

Ip $=0.009 ; \S p<0.05$ (Kruskal Wallis test comparing different regions of the upper gastrointestinal tract).

\section{Statistical analyses}

Data are presented as medians and interquartile range unless otherwise stated. For the microdialysis experiments, the Kruskal-Wallis test was used to analyse concentrations of the chemicals of nitrosation in the different regions of the upper gastrointestinal tract for pre and post-nitrate data. Comparison between pre and post-nitrate microdialysis data was analysed using the one sample Wilcoxon test. Serum nitrate, salivary nitrite, and thiocyanate data, and $\mathrm{pH}$ of the different regions of the upper gastrointestinal tract were analysed using the one sample Wilcoxon test with Bonferroni's correction.

For the nitric oxide experiment, serum nitrate and salivary nitrite concentrations were grouped into pre and post-nitrate periods and analysed by the one sample Wilcoxon test.

For analysis of ascorbic acid to total vitamin $\mathrm{C}$ ratio, if both ascorbic acid and total vitamin $\mathrm{C}$ were undetectable from the single sample, the sample was excluded from statistical analysis.

In order to calculate the ascorbic acid to nitrite ratio, any samples with undetectable levels of ascorbic acid or nitrite concentrations were allocated a concentration of $1 \mu \mathrm{M}$, the approximate lower limit of detection for both ascorbic acid and nitrite using our analytic methods. If both ascorbic acid and nitrite were undetectable, these samples were excluded from analysis. The Kruskal-Wallis test was used to analyse the ascorbic acid to nitrite ratio in the different regions before and after nitrate ingestion. A two tailed $\mathrm{p}<0.05$ was considered statistically significant.

For the nitric oxide experiment, the small numbers precluded meaningful statistical testing. Data are presented before and after nitrate administration for individual patients.

\section{Ethics}

The study was approved by the North Glasgow University NHS Trust Ethics Committee and each subject gave written informed consent.

\section{RESULTS}

Fourteen subjects with Barrett's oesophagus consented to the study. Four could not tolerate the procedure and therefore results are available for 10 subjects. Mean age of the subjects was 65 years (range 48-70) and four were female. Median length of Barrett's segment was $5 \mathrm{~cm}$ (range 3-12) for the 10 patients in the microdialysis experiment.

\section{Studies employing microdialysis probes \\ Serum}

Serum nitrate concentration just prior administration of the nitrate solution was $13.0 \mu \mathrm{M}(12.3-19.8)$. It increased to
$49.4 \mu \mathrm{M} \quad(31.9-65.0) \quad(\mathrm{p}<0.01 \quad v \quad 45$ minutes pre-nitrate $)$ 40 minutes after nitrate was administered and remained at this level throughout the remainder of the experiment.

\section{Saliva}

Saliva nitrite concentration before insertion of the probe assembly was $73.1 \mu \mathrm{M}(61.8-216.4)$ and decreased to $35.0 \mu \mathrm{M}(26.3-78.9)$ at 15 minutes after its insertion. Following administration of nitrate, saliva nitrite concentration increased from $56.3 \mu \mathrm{M}(23.2-82.6)$ just before nitrate administration to a peak of $351.4 \mu \mathrm{M}(107.8-405.0)$ at 85 minutes after nitrate administration $(\mathrm{p}<0.01 \vee 45$ minutes pre-nitrate) (fig 1).

Saliva thiocyanate concentration just before passing the probe assembly was $794 \mu \mathrm{M}(682-1339)$ and was similar at $770 \mu \mathrm{M}$ (459-1446) 15 minutes after placement of the assembly. Thiocyanate concentrations remained at a similar concentration after administration of nitrate.

\section{$\mathrm{pH}$ of individual regions of the upper gastrointestinal tract}

Median (range) pH in the squamous oesophagus, Barrett's oesophagus, hiatal hernia, and proximal and distal stomach were $6.2(5.0-7.7) \quad(p<0.05 v$ all other sites $), 2.7$ (1.4-7.5) $(\mathrm{p}<0.05 v$ hiatal hernia, and proximal and distal stomach), 1.4 (1.1-3.9), 1.4 (1.0-2.1), and 1.4 (1.1-1.9), respectively, before nitrate administration, and $5.7(2.9-7.2)(\mathrm{p}<0.05 v$ all other sites), $2.7(1.6-7.1) \quad(\mathrm{p}<0.05 \quad v$ hiatal hernia, and proximal and distal stomach), $1.6(0.8-2.1), 1.5$ (1.1-1.8), and $1.4(1.1-1.6)$ after nitrate administration.

The $\mathrm{pH}$ was greater than 4 for $94 \%$ (61.9-100), 18.7\% (0.9$42.3), 0 \%(0-0.2), 0 \%$, and $0 \%$ in the squamous oesophagus, Barrett's segment, hiatus hernia, proximal stomach, and distal stomach, respectively, before nitrate administration. After nitrate administration the respective per cent $\mathrm{pH}>4$ values were $92 \%$ (56.3-98.2), 3.6\% (1.2-15.3), $0 \%, 0 \%$, and $0 \%$ (all NS $v$ pre-nitrate).

\section{Microdialysis nitrite}

Before nitrate administration, the nitrite concentration within the squamous oesophagus was $40.1 \mu \mathrm{M}$ (12.7-63.4) (table 1 ) and thus similar to values in buccal saliva $(35.0 \mu \mathrm{M}$ (26.3-78.9)). Nitrite concentrations were substantially lower in Barrett's segment $(0 \mu \mathrm{M}(0-5.9))$ and in the hiatus hernia $(0 \mu \mathrm{M}(0-0.3))$, and no nitrite was detected in the proximal or distal stomach.

Following nitrate administration, the nitrite concentration in the squamous oesophagus increased to $106.2 \mu \mathrm{M}$ (75.7141.6) ( $\mathrm{p}=0.03$ versus pre-nitrate) (table 1$)$. However, there was no significant change in nitrite concentrations in 


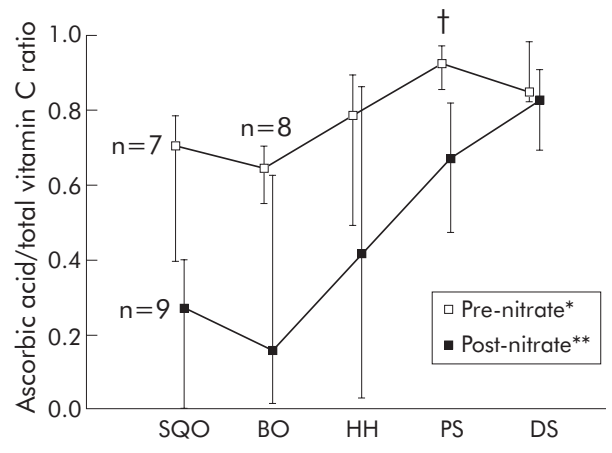

Figure 2 Median (interquartile range) ascorbic acid to total vitamin $\mathrm{C}$ ratio before and after nitrate. SQO, squamous oesophagus; $\mathrm{BO}$, Barrett's oesophagus; $\mathrm{HH}$, hiatus hernia; PS, proximal stomach; DS, distal stomach. $n=10$ unless otherwise indicated. ${ }^{*} p=0.028$ (Kruskal Wallis analysis for the different anatomical sites); ${ }^{* *} p=0.048$ (Kruskal Wallis analysis for the different anatomical sites); $\uparrow p=0.018$ pre versus post nitrate.

Barrett's segment, hiatus hernia, or in the proximal or distal stomach.

\section{Microdialysis thiocyanate}

Prior to nitrate administration, thiocyanate concentration was similar in the squamous oesophagus, Barrett's segment, hiatal hernia, proximal stomach, and distal stomach, and did not change following nitrate administration (table 1 ). Thiocyanate concentrations at these sites were approximately $50 \%$ of those in saliva.

Microdialysis ascorbic acid and total vitamin C Prior to nitrate administration, ascorbic acid and total vitamin $\mathrm{C}$ concentrations progressively increased from the squamous oesophagus to the distal stomach. Ascorbic acid concentrations for the squamous oesophagus, Barrett's segment, hiatal hernia, and the proximal and distal stomach were $3.5 \mu \mathrm{M}(0-11.7), 9.9 \mu \mathrm{M}$ (3.4-16.8), $27.7 \mu \mathrm{M}$ (6.7$42.5), 38.4 \mu \mathrm{M}(20.6-66.6)$, and $43.4 \mu \mathrm{M}$ (24.1-68.5), respectively $(\mathrm{p}<0.001$ for trend) (table 1$)$. Total vitamin C concentrations for these respective regions were $3.8 \mu \mathrm{M}(0-$ 14.7), 19.1 $\mu \mathrm{M}$ (5.1-32.2), 34.1 $\mu \mathrm{M}$ (10.2-47.5), 41.1 $\mu \mathrm{M}$ (24.9-77.0), and 58.9 $\mathrm{MM}(22.6-72.8)(\mathrm{p}=0.001$ for trend).

Following nitrate administration, ascorbic acid concentrations for the squamous oesophagus, Barrett's segment, hiatal hernia, proximal stomach, and distal stomach were $1.2 \mu \mathrm{M}$ $(0-12.4), 2.9 \mu \mathrm{M}(0.2-32.4), 14.7 \mu \mathrm{M}(0-42.7), 28.4 \mu \mathrm{M}(9.1-$ 45.4), and $48.6 \mu \mathrm{M}(17.0-73.6)$, respectively $(\mathrm{p}=0.009$ for trend) (NS $v$ pre-nitrate) (table 1). Post-nitrate concentrations of total vitamin $\mathrm{C}$ for the respective regions were $5.6 \mu \mathrm{M}$ (0.4-34.3), $23.4 \mu \mathrm{M} \quad(13.4-28.4), \quad 33.4 \mu \mathrm{M}$ (21.5-44.9), $35.6 \mu \mathrm{M}(18.3-71.2)$, and $46.5 \mu \mathrm{M}(20.0-78.7) \quad(\mathrm{p}<0.05$ for trend) (NS $v$ pre-nitrate).

Median ascorbic acid to total vitamin $\mathrm{C}$ ratios before nitrate administration for squamous oesophagus, Barrett's segment, hiatal hernia, proximal stomach, and distal stomach were $0.70(0.4-0.78)(\mathrm{n}=7), 0.64(0.55-0.70)(\mathrm{n}=8), 0.78(0.49-$ $0.89), 0.93(0.86-0.97)$, and $0.85(0.82-0.98)$, respectively $(\mathrm{p}=0.02$ for trend) (fig 2). After nitrate administration, median ascorbic acid to total vitamin $\mathrm{C}$ ratios were $0.27(0-$ $0.4)(\mathrm{n}=9), 0.16(0.02-0.63), 0.42(0.03-0.86), 0.67(0.47-$ $0.82)$, and $0.83(0.69-0.91)(\mathrm{p}=0.048$ for trend $)(\mathrm{p}=0.018$ for proximal stomach pre-nitrate $v$ post-nitrate) (fig 2 ). Thus the ratio of ascorbic acid to total vitamin $\mathrm{C}$ was lowest within Barrett's segment. In addition, the ratio fell after nitrate administration but this only reached statistical significance for the proximal stomach $(\mathrm{p}<0.02)$.
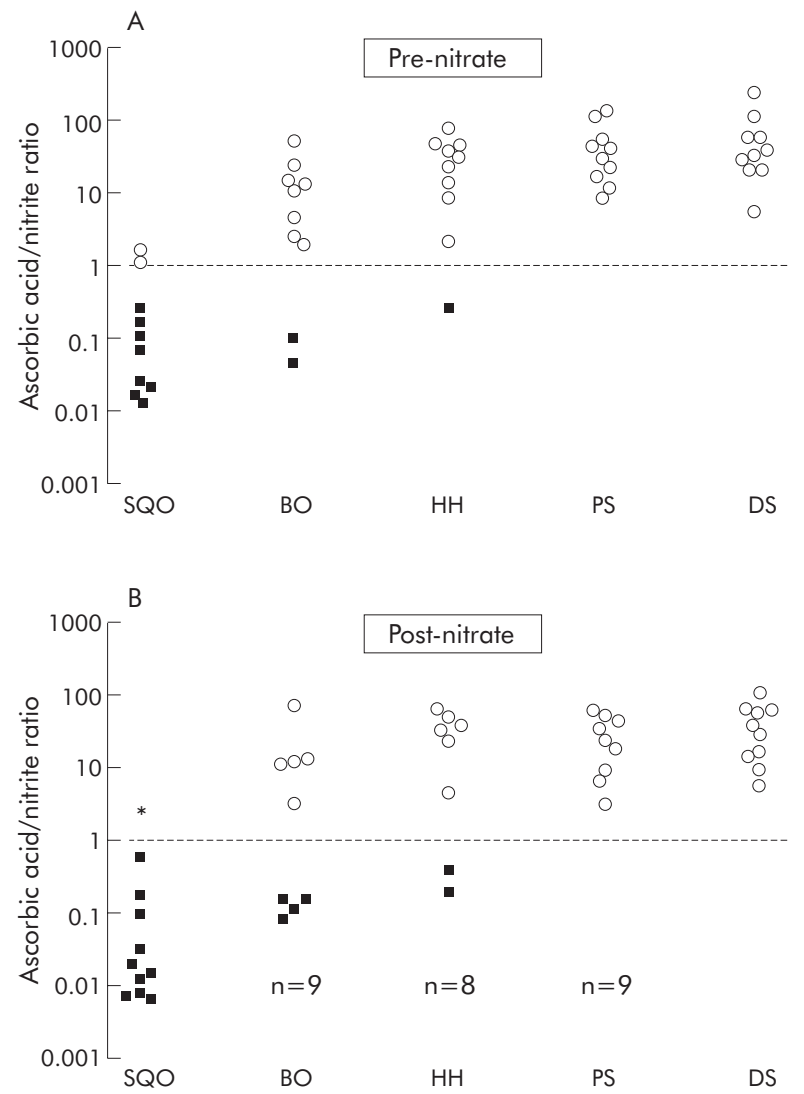

Figure 3 Ascorbic acid to nitrite ratio before (A) and after (B) nitrate administration. SQO, squamous oesophagus; BO, Barrett's oesophagus; $\mathrm{HH}$, hiatal hernia; PS, proximal stomach; DS, distal stomach. Open symbols indicate condition unfavourable for acid catalysed nitrosation; closed symbols indicate condition favourable for acid catalysed nitrosation. Note that acid catalysed nitrosation does not occur in the SQO at neutral PH. $\mathrm{p}<0.001$ for trend both before and after nitrate administration; ${ }^{*} \mathrm{p}=0.032$ versus pre-nitrate administration.

\section{Microdialysis ascorbic acid to nitrite ratio}

The ascorbic acid to nitrite ratio provides an indication of the potential for luminal acid nitrosation as the latter only occurs in acidic $\mathrm{pH}$ when nitrite is present in excess of available ascorbic acid. Median (interquartile range) ascorbic acid to nitrite ratios progressively increased at each more distal site being 0.1 (0.02-0.47), 7.4 (1.6-16.8), 26.2 (6.7-42.5), 32.3 (15.1-65.2), and 32.7 (18.9-68.5) in squamous oesophagus, Barrett's segment, hiatal hernia, proximal stomach, and distal stomach, respectively, before nitrate administration $(\mathrm{p}<0.001$ for trend) (table 1, fig 3 ). A similar pattern was observed after nitrate where the respective ratios were 0.02 (0.01-0.13) $(\mathrm{p}=0.032 v$ squamous pre-nitrate), $3.4(0.14-$ 12.4) $(\mathrm{n}=9), 29.2(1.5-47.9)(\mathrm{n}=8), 25.0(8.5-48.5)(\mathrm{n}=9)$, and $34.2(13.8-64.3)(\mathrm{p}<0.001$ for trend) (table 1, fig 3$)$. The only anatomical sites favouring luminal acid nitrosation were in Barrett's segment where two of 10 subjects before nitrate and four of nine after nitrate had acidic nitrite in excess of ascorbic acid, and within the hiatus hernia in one of 10 before nitrate and two of eight after nitrate. In the proximal and distal stomach, all subjects had ascorbic acid in excess of nitrite.

\section{Nitric oxide experiments}

Nitric oxide was measured in three patients both before and after nitrate administration. The change in hospital regulation for cleaning the equipments used in human subjects from gluteraldehyde to Sterilox had an adverse effect on the 


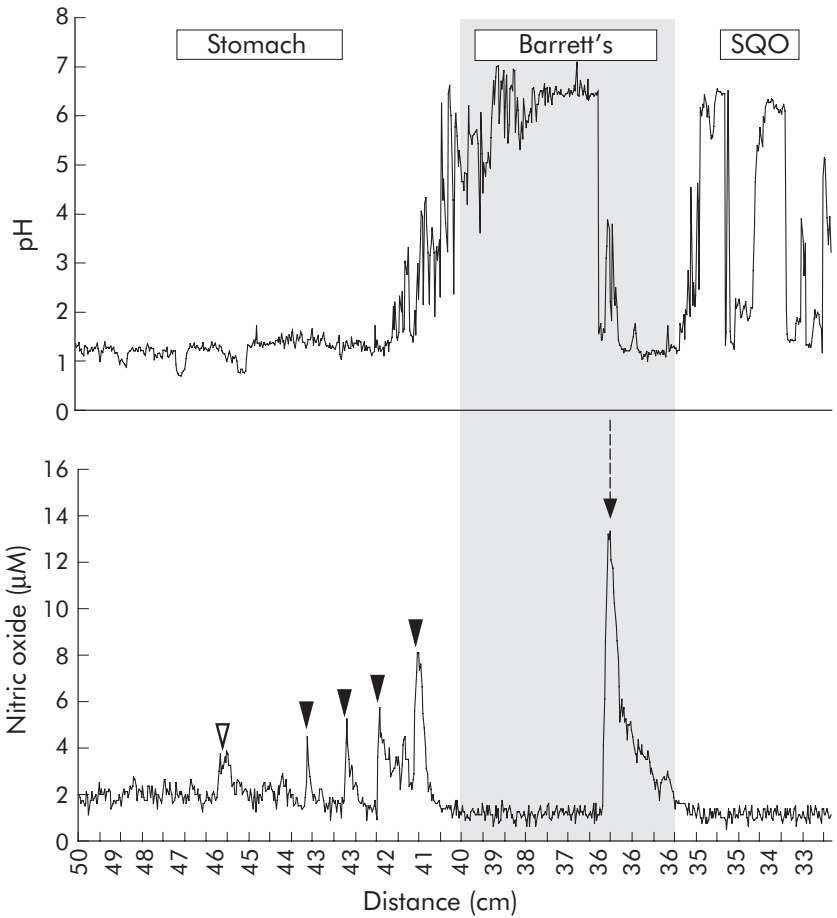

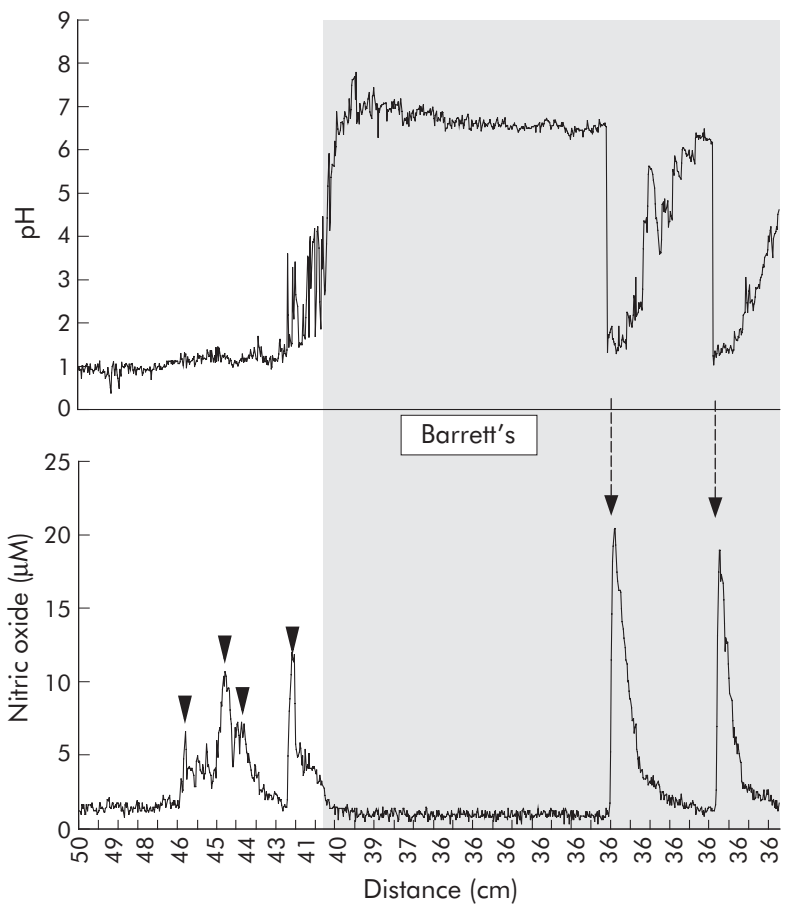

Figure 4 (A) Simultaneous recording of $\mathrm{pH}$ and nitric oxide before nitrate ingestion in patient No 1 . The shaded area indicates recordings within Barrett's segment $(40-30 \mathrm{~cm})$. SQO, squamous oesophagus. There was a small amount of nitric oxide generated in the proximal stomach at $46 \mathrm{~cm}$ (open arrowhead). Nitric oxide was generated just distal to the gastro-oesophageal junction (solid arrowheads), indicated by the step up in $\mathrm{pH}$. $\mathrm{A}$ reflux event in Barrett's segment generated $12 \mu \mathrm{M}$ of nitric acid as pH fell from 6.5 to 1.5. No nitric oxide was generated in the squamous oesophagus during the three reflux episodes. (B) Simultaneous recording of $\mathrm{pH}$ and nitric oxide after nitrate ingestion in patient No 1. The shaded area indicates recordings within Barrett's segment. Nitric oxide was generated just distal to the gastro-oesophageal junction $(42-41 \mathrm{~cm})$ and in the proximal stomach $(46-44 \mathrm{~cm})$ (arrowheads). No nitric oxide was produced in Barrett's segment (shaded area) between pH 6 and 7 . Two acid reflux events in Barrett's segment at $36 \mathrm{~cm}$ generated $20 \mu \mathrm{M}$ of nitric acid (broken arrows).

longevity of the nitric oxide probe and we could only perform experiments on three subjects before the probe malfunctioned. Their median serum nitrate concentration during the 45 minute interval before nitrate administration was $19.2 \mu \mathrm{M}(14.3-30.2)$ and following nitrate administration significantly higher at 62.4 $\mu \mathrm{M}(40.9-65.7)(\mathrm{p}=0.004)$. Their median salivary nitrite increased from $113.8 \mu \mathrm{M}$ (36.9-150.8) during the 45 minute interval before nitrate administration to $254.1 \mu \mathrm{M}$ (142.7-375.8) during the 45 minute interval, 15 minutes after nitrate administration $(\mathrm{p}=0.02)$.

The first subject was a 59 year old female with a $4 \mathrm{~cm}$ Barrett's mucosa. Before nitrate, small rises in nitric oxide, up to $8.1 \mu \mathrm{M}$, were observed on passing through the gastric cardia. Within Barrett's segment, an episode of acid reflux caused an immediate rise in nitric oxide to $13.4 \mu \mathrm{M}$ but in the squamous oesophagus, nitric oxide generation was not observed following the three reflux episodes (fig 4A). Following nitrate, two episodes of acid reflux were observed within Barrett's segment and both produced an immediate and marked rise in nitric oxide concentration of approximately $20 \mu \mathrm{M}$ (fig 4B).

The second subject was a 65 year old female with a $5 \mathrm{~cm}$ Barrett's mucosa. Before nitrate, a single acid reflux to pH 3.5 was recorded within Barrett's segment but there was no rise in nitric oxide concentration (fig 5A). Following nitrate administration, there were frequent episodes of acid reflux into Barrett's segment and these resulted in marked increases in nitric oxide up to $59 \mu \mathrm{M}$ within Barrett's segment (fig 5B).

The third subject was a 69 year old male with a $5 \mathrm{~cm}$ Barrett's mucosa. Prior to nitrate administration, a rise in nitric oxide concentration to $25 \mu \mathrm{M}$ was observed on pulling the probe through the stomach at $45 \mathrm{~cm}$. Approximately
$8 \mu \mathrm{M}$ of nitric oxide was generated at $39 \mathrm{~cm}$ as saliva came into contact with gastric juice. The probe was then maintained at $35 \mathrm{~cm}$ at the upper margin of Barrett's segment. When acid refluxed into this segment there was an immediate rise in nitric oxide concentration to $7 \mu \mathrm{M}$ at this site (fig 6A). Following nitrate administration, rises in nitric oxide were again observed on passing through the proximal stomach/hiatus hernia. When the probe was then maintained in Barrett's segment, again intermittent falls in $\mathrm{pH}$ due to acid reflux were accompanied by rises in nitric oxide of varying magnitude (fig 6B).

\section{DISCUSSION}

Swallowed saliva is the main source of nitrite entering the upper gastrointestinal tract. The high concentration of nitrite in saliva is due to salivary glands secreting high concentrations of nitrate which is reduced to nitrite by buccal bacteria. ${ }^{4-6}$ Circulating nitrate, which is taken up and secreted by salivary glands, is mainly derived from the diet although some is the end product of enzymatically generated nitric oxide. ${ }^{4126}$ Nitrite is a relatively inert chemical at neutral pH but on acidification becomes highly reactive as both an oxidative and nitrosative compound. Our studies indicate that during episodes of acid reflux this potentially mutagenic nitrite chemistry is focused within the distal oesophagus.

The conditions required for acid catalysed generation of $\mathrm{N}$-nitroso compounds are pH of less than 4 , nitrite in excess of ascorbic acid, and thiocyanate to catalyse the reaction. ${ }^{421} 23$ Our studies indicate that during acid reflux, these conditions are confined to Barrett's segment and to a lesser extent within the hiatus hernia. Within Barrett's segment, two of the 10 subjects had acidified nitrite in excess of ascorbic acid 

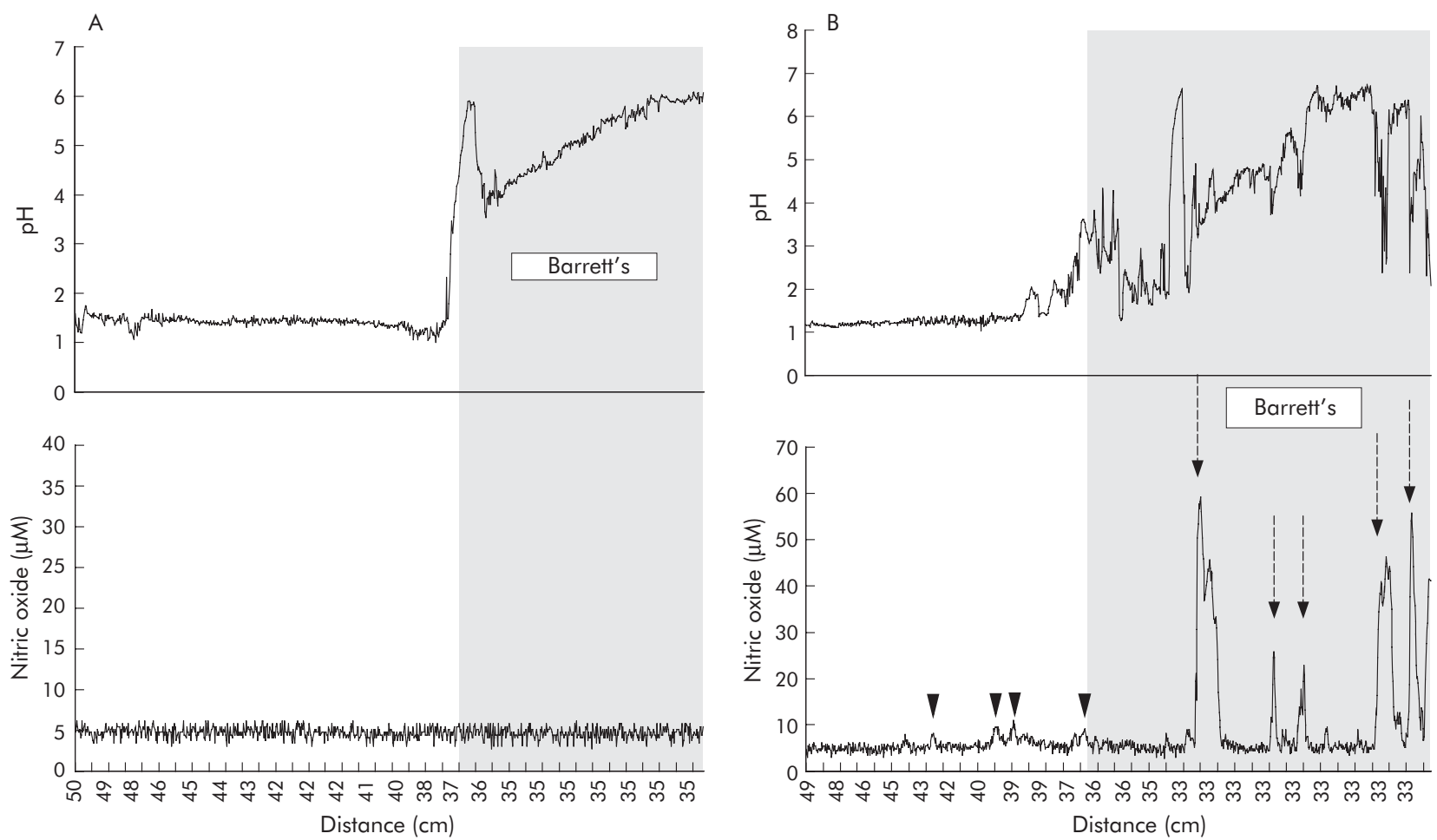

Figure 5 (A) Simultaneous recording of $\mathrm{pH}$ and nitric oxide before nitrate ingestion in patient $\mathrm{No}$ 2. The shaded area indicates recordings within Barrett's segment (36-33 cm). The background "noise" giving a nitric oxide concentration of $5 \mu \mathrm{M}$ was not corrected. No significant acid reflux was recorded in Barrett's segment and no nitric oxide generation was detected. (B) Simultaneous recording of $\mathrm{pH}$ and nitric oxide after nitrate ingestion in patient No 2. The shaded area indicates recordings in Barrett's segment $(36-33 \mathrm{~cm})$. Small amounts of nitric oxide were generated in the proximal stomach (arrowheads). At $33 \mathrm{~cm}$, within Barrett's segment, up to $56.5 \mu \mathrm{M}$ of nitric oxide were generated when acid reflux occurred (broken arrows).

before nitrate and four of nine after nitrate (fig 3). Within the hiatus hernia, one of 10 patients had acidified nitrite in excess of ascorbic acid before nitrate and two of eight after nitrate. In the proximal and distal stomach, ascorbic acid was always in excess of nitrite. In the more proximal squamous oesophagus, nitrite was present in considerable excess of ascorbic acid but $\mathrm{pH}$ remained $>4$ and thus acid nitrosation could not occur.

Following insertion of the microdialysis assembly, salivary nitrite concentration fell by approximately 50\%. This has been observed previously ${ }^{18}$ and may be explained by the microdialysis apparatus stimulating increased salivary flow and swallowing. Consequently, saliva will be in the mouth for a shorter period of time and thus less converted to nitrite by buccal bacteria.

A marked finding in this study was the fall in luminal nitrite concentration on passing from the proximal squamous oesophagus into Barrett's segment exposed to acidic gastric refluxate (table 1). In previous studies we have examined nitrite concentrations at multiple sites in the oesophagus and stomach of normal volunteers without gastro-oesophageal reflux. In such subjects, high concentrations of nitrite were found throughout the length of the oesophagus and a marked fall in concentration occurred on entering the acidic environment of the gastric cardia. ${ }^{18}$ We have also previously studied luminal nitrite concentrations in subjects on omeprazole with high intragastric $\mathrm{pH}$ and observed that nitrite concentrations within their stomach were similar to those of their saliva. ${ }^{25}{ }^{27}$ Thus the nitrite concentrations seem to fall at the point where neutral luminal $\mathrm{pH}$ first drops to acidic luminal $\mathrm{pH}$.

What is the mechanism of disappearance of nitrite swallowed in saliva on encountering gastric acid and in the current studies occurring within Barrett's segment? When nitrite passes from the neutral $\mathrm{pH}$ of the proximal oesophagus into the acidic environment of refluxing gastric juice in Barrett's oesophagus, it will be converted immediately to nitrous acid ( $\mathrm{pKa}$ for nitrous acid =3.5). However, this in itself cannot explain the marked fall in measured nitrite within Barrett's oesophagus as the microdialysis probes do not distinguish between nitrous acid and nitrite. ${ }^{20}$ The marked fall in luminal nitrite/nitrous acid concentration on entering Barrett's segment suggests that it is being absorbed by the epithelium, converted to a different chemical, or both. Nitrous acid is less polar than the nitrite anion and the latter may be more readily absorbed. However, the ability to absorb substances depends on their ionic state at the mucosal surface and this depends on epithelial surface $\mathrm{pH}$. Columnar mucosa, including Barrett's epithelium, has a mucus layer and, like mucosa of similar phenotype in the stomach and small intestine, is likely to secrete bicarbonate into the mucous layer to maintain a neutral surface $\mathrm{pH}^{28}$ Consequently, nitrous acid would be in the form of the nitrite anion at the epithelial surface and therefore not readily absorbed. It therefore seems unlikely that disappearance of nitrite within Barrett's segment can be attributed to a significant extent by its absorption as either nitrite or nitrous acid.

Another explanation for the disappearance of nitrite/ nitrous acid on entering the acidic lumen of Barrett's segment is its conversion to nitric oxide. The microdialysis probes do not detect nitric oxide. ${ }^{20}$ At pH less then 3.5, approximately $1-2 \%$ of nitrous acid exists as nitric oxide. ${ }^{29}$ However, in the presence of acid plus a reducing agent such as ascorbic acid, nitrous acid is rapidly converted to nitric oxide. $^{29}$ Stoichemically, $1 \mathrm{~mol}$ of ascorbic acid reacts with 2 mole of nitrous acid forming $2 \mathrm{~mol}$ of nitric oxide and 1 mol of dehydroascorbic acid. ${ }^{30}$ In our study, we found that 

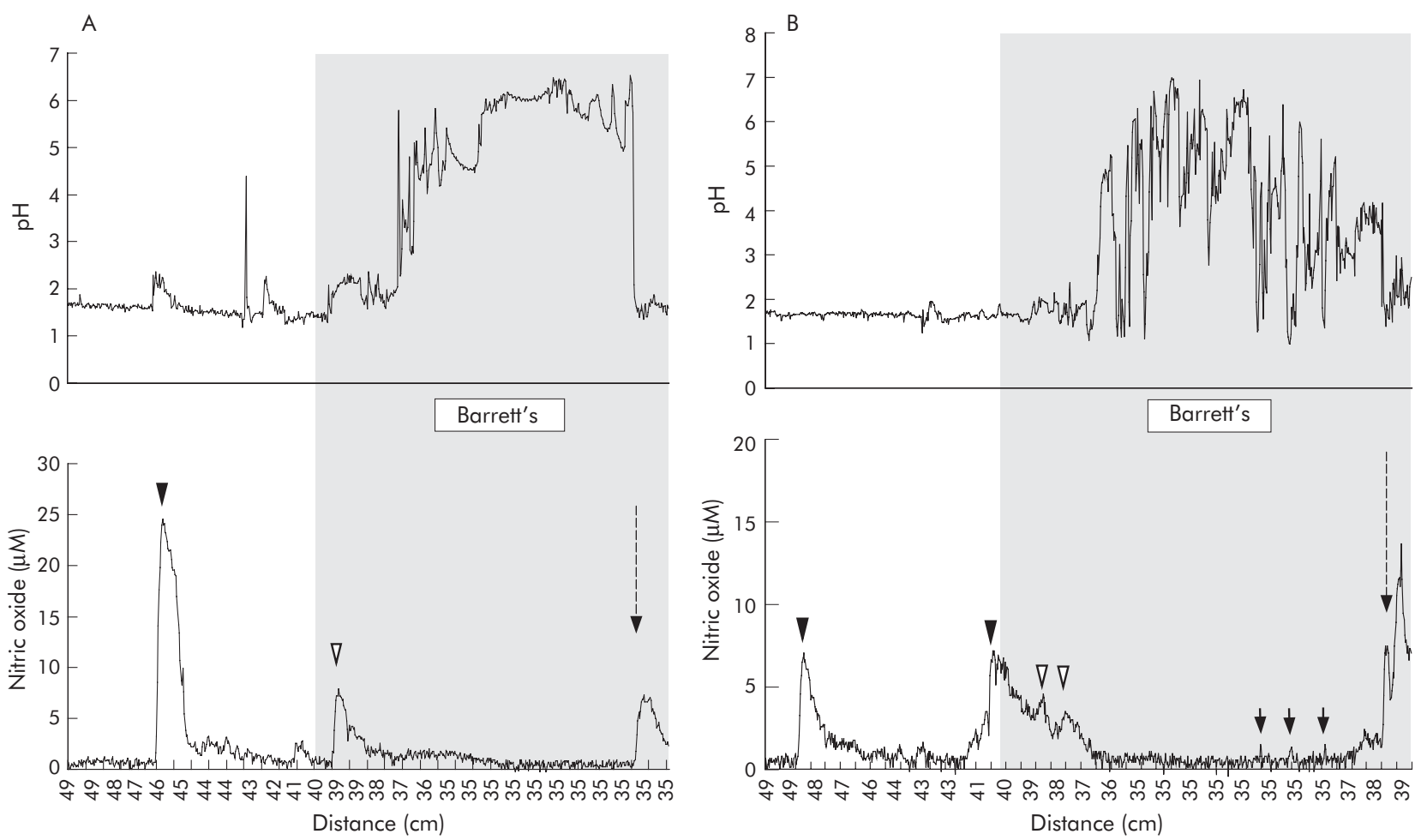

Figure 6 (A) Simultaneous recording of $\mathrm{pH}$ and nitric oxide before nitrate ingestion in patient No 3 . The shaded area indicates recordings within Barrett's segment $(40-35 \mathrm{~cm})$. Nitric oxide generation seen in the proximal stomach at $45-46 \mathrm{~cm}$ (solid arrowhead) coincided with slight rise in pH due to swallowed saliva. Smaller concentrations of nitric oxide were generated in Barrett's segment: one coinciding with a slight rise in pH due to swallowed saliva (open arrowhead) and another during acid reflux in a segment with a neutral $\mathrm{pH}$ (broken arrow). (B) Simultaneous recording of $\mathrm{pH}$ and nitric oxide after nitrate ingestion in patient No 3. The shaded area indicates recording within Barrett's segment $(40-35 \mathrm{~cm})$. Nitric oxide generation was seen in the stomach from 49 to $41 \mathrm{~cm}$ (solid arrowheads). Small amounts of nitric oxide were generated within Barrett's segment at $35 \mathrm{~cm}$, coinciding with reflux episodes (solid arrows) as well as at $39-37 \mathrm{~cm}$, coinciding with a slight rise in pH due to swallowed saliva (open arrowheads). A reflux episode at $39 \mathrm{~cm}$ generated $13.5 \mu \mathrm{M}$ of nitric oxide (broken arrow).

the proportion of ascorbic acid to total vitamin C (that is, ascorbic acid plus dehydroascorbic acid) was lowest in Barrett's segment and this was the case both before and after nitrate administration (fig 2). This pattern is consistent with nitrite in swallowed saliva reacting with ascorbic acid within the acidic Barrett's segment, resulting in nitrite being reduced to nitric oxide and ascorbic acid to dehydroascorbic acid. The ratio of ascorbic acid to total vitamin C was also low in the squamous oesophagus, particularly after nitrate, despite this being at a neutral $\mathrm{pH}$ (table 1, fig 2). This may be explained by ascorbic acid originating from the stomach and being oxidised by the acidified nitrite as it refluxes past Barrett's segment to reach the proximal squamous mucosa.

We were able to perform supplementary studies in three subjects to determine whether nitric oxide was being generated within Barrett's segment during episodes of acid reflux. A number of reasons prevented us from undertaking nitric oxide studies in all of the subjects. Several of the patients could not tolerate the rather bulky custom made nitric oxide probe. In addition, changes in legislation regarding disinfection meant that we had to utilise Sterilox for all internal instrumentation. Unfortunately, the metal construction and membrane of the probe could not tolerate the chemical process. In the supplementary studies we were able to conduct, approximately $50 \%$ of the episodes of acid reflux resulted in the immediate appearance of very high concentrations of nitric oxide within Barrett's segment (figs 4-6). This is consistent with the acidic gastric juice and its ascorbic acid content converting the nitrite in saliva within the oesophageal lumen to nitric oxide. In a proportion of the acid reflux episodes, very little or no nitric oxide was detected in Barrett's segment. Several reasons may explain the variation in intraoesophageal nitric oxide associated with acid reflux. The nitric oxide probe only detects the concentration of nitric oxide at its tip and thus within a very localised region. The site of nitric oxide generation within the oesophagus will be maximal where the refluxing acid meets the saliva and this is likely to vary depending on the magnitude of the reflux episode and the amount and site of saliva within the oesophageal lumen. In addition, preceding reflux episodes may deplete local concentrations of ascorbic acid and or nitrite and thus prevent nitric oxide generation at that site.

Our studies indicate that very active nitrite chemistry occurs within Barrett's oesophagus during acid reflux. The fall in $\mathrm{pH}$ due to acid reflux converts nitrite within the oesophageal lumen to nitrous acid and the nitrosating species $\mathrm{N}_{2} \mathrm{O}_{3}$ and $\mathrm{NO}^{+}$and NOSCN. These nitrosating species are then reduced by available ascorbic acid producing nitric oxide and dehydroascorbic acid. As all of this nitrosative chemistry arises from the reaction between saliva and acidic gastric juice, it is focused within the oesophagus during acid reflux. In the absence of reflux it is focused at the gastric cardia. ${ }^{18} 19$

In our current studies we examined patients with Barrett's oesophagus and severe gastro-oesophageal reflux. We chose Barrett's patients as they are the subject group with the greatest oesophageal acid exposure. ${ }^{31-37}$ The microdialysis probes need to be in place for 40 minutes to obtain sufficient volume of sample for analysis. Consequently, they reflect the mean concentration over that 40 minute period. As we wished to measure what happens during reflux, we therefore chose subjects with severe reflux so that reflux would be 
occurring for most of the recording period. It was for this same reason that we gave low dose pentagastrin to stimulate gastric secretion and also used the supine position to promote gastro-oesophageal reflux. From the present studies we cannot say whether the luminal chemistry observed during reflux in Barrett's patients differs from that in non-Barrett's patients with an equivalent degree of reflux.

The clinical significance of this nitrosative chemistry occurring in the distal oesophagus during acid reflux is currently unclear. However, acid reflux is known to induce changes in the oesophageal epithelium, including erosive oesophagitis, metaplasia, and neoplasia. Most research has focused on the direct noxious effects of acid on the oesophageal epithelium. However, our current studies indicate that acid reflux may activate another and indirect pathway which may contribute to oesophageal metaplasia and dysplasia. The nitrosating species generated within the oesophagus during the reaction between the acidic refluxate and oesophageal nitrite may exert nitrosative and oxidative stress on the epithelium and result in local generation of potentially carcinogenic $N$-nitroso compounds. The very high luminal concentrations of nitric oxide generated within the oesophagus by acid reflux may also have damaging effects as such concentrations have been shown to be mutagenic. ${ }^{38-40}$ High concentrations of nitric oxide can exert nitrosative and oxidative stress, damaging DNA and inhibiting a number of key DNA repair enzymes. ${ }^{15-17}$ In rats, oral coadministration of nitrite plus ascorbic acid or other antioxidants produces tumours of the proximal stomach-an effect which did not occur when nitrite or antioxidants were administered alone. ${ }^{41} 42$ The combined administration of nitrite plus antioxidant will produce high concentrations of nitric oxide. More recent studies in mice have observed that intragastric administration of single large doses of nitrite plus ascorbic acid produce DNA damage within the cells of the gastric epithelium and this effect was again attributed to generation of nitric oxide within the gastric lumen. ${ }^{43}$

In animal models, oesophageal epithelium subject to damage by duodenogastro reflux is known to be more sensitive to the mutagenic effects of luminal $\mathrm{N}$-nitroso compounds. ${ }^{43-46}$ A synergistic interaction may therefore occur during gastro-oesophageal reflux. Erosion of the oesophageal mucosal surface by acidic reflux will make basal epithelial stem cells more exposed to the luminal nitrite chemistry activated by the same acidic reflux. In addition, acid reflux stimulates basal cell proliferation and replicating DNA will be more sensitive to the mutagenic effects of the nitrosative chemistry, again activated by the same acid reflux. ${ }^{47-50}$

In conclusion, our current studies demonstrate that potentially mutagenic nitrite chemistry occurs within the oesophageal lumen during acid reflux. This arises from the reaction between the refluxing acidic gastric juice and swallowed saliva. At present, it is unclear whether this is contributing to the oesophageal epithelial damage and development of metaplasia and neoplasia associated with chronic acid reflux. However, it is important to investigate this possibility as such an effect could be modified by altering nitrate intake and/or its conversion to nitrite by buccal organisms.

\section{ACKNOWLEDGEMENTS}

The study was funded by the Clinical and Biomedical Research Committee of the Scottish Home and Health Department.

\author{
Authors' affiliations \\ H Suzuki, K liijima, G Scobie, V Fyfe, K E L McColl, University of \\ Glasgow, Glasgow, UK \\ Conflict of interest: None declared.
}

\section{REFERENCES}

1 Botterweck AAM, Schouten $\amalg$, Volovics A, et al. Trends in incidence of adenocarcinoma of the oesophagus and gastric cardia in ten European countries. Int J Epidemiol 2000;29:645-54.

2 El-Serag HB. The epidemic of esophageal adenocarcinoma. Hematol Oncol Clin N Am 2003;17:413-32.

3 Lagergren J, Bergstrom R, Lindgren A, et al. Symptomatic gastroesophageal reflux as a risk factor for esophageal adenocarcinoma. N Engl J Med 1999;340:825-31.

4 Bartholomew B, Hill MJ. The pharmacology of dietary nitrate and the origin of urinary nitrate. Food Chem Toxicol 1984;22:789-95.

5 Granli T, Dahl R, Brodin P, et al. Nitrate and nitrite concentrations in human saliva: variations with salivary flow-rate. Food Chem Toxicol. 1989;27: 10, 675-80.

6 van Maanen JM, van Geel AA, Kleinjans JC. Modulation of nitrate-nitrite conversion in the oral cavity. Cancer Detect Prev 1996;20:590-6.

7 Documenta Geigy Scientific Tables, 6th Edn., Manchester: Geigy Pharmaceutical Company 1975.

8 Leach S. Mechanisms of endogenous N-nitrosation. In: Hill J, eds. Nitrosoamines: toxicology and microbiology. Chichester: Ellis Horwood, 1988:69-87.

9 Mirvish SS. Role of N-nitroso compounds (NOC) and N-nitrosation in etiology of gastric, esophageal, nasopharyngeal and bladder cancer and contributiion to cancer of known exposures to NOC. Cancer Lett 1995;93:17-48.

10 Schorah CJ, Sobala GM, Sanderson M, et al. Gastric juice ascorbic acid: effects of disease and implications for gastric carcinogenesis. Am J Clin Nutr 1991;53:287S-93.

11 Archer MC, Tannenbaum SR, Fan T-Y, et al. Reaction of nitrite with ascorbate and its relation to nitrosoamine formation. J Natl Cancer Inst 1975;54:1203-5.

12 McKnight GM, Smith LM, Drummond RS, et al. Chemical synthesis of nitric oxide in the stomach from dietary nitrate in humans. Gut 1997;40:211-14.

13 Lundberg JON, Weitzberg E, Lundberg JM, et al. Intragastric nitric oxide production in humans: measurements in expelled air. Gut 1994;35:1543-6.

14 lijima K, Grant J, McElroy K, et al. Novel mechanism of nitrosative stress from dietary nitrate with relevance to gastro-oesophageal junction cancers. Carcinogenesis. 2003;24: 12, 1951-60.

15 Wink DA, Fellisch M, Vodovotz Y, et al. In: Gilbert DL, Coton CA, eds. Reactive oxygen species in biological systems. New York: Kluwer Academic/ Plenum Publishers, 1999:245-92

16 Liu L, Xu-Welliver M, Kanugula S, et al. Inactivation and degradation of $\mathrm{O}^{6}$ alkylguanine-DNA alkyltransferase after reaction with nitric oxide. Cancer Res 2002;62:3037-43.

17 O'Connor T, Graves RV, Murcia G, et al. Fpg protein of E. coli is a zinc finger protein whose cysteine residues have a structural and/or functional role. J Biol Chem 1993;268:9063-70.

18 Suzuki H, lijima K, Moriya A, et al. Conditions for acid catalysed luminal nitrosation are maximal at the gastric cardia. Gut 2003;52:1095-101.

19 lijima K, Henry E, Moriya A, et al. Dietary nitrate generates potentially mutagenic concentrations of nitric oxide at the gastroesophageal junction. Gastroenterology 2002;122:1248-57.

20 Suzuki H, Moriya A, lijima K, et al. Validation of microdialysis probes for studying nitrosative chemistry within localized regions of the human upper gastrointestinal tract. Scand J Gastroenterol 2003;38:856-63.

21 Walker R. Nitrates, nitrites and $\mathrm{N}$-nitrosocompounsd: a review of the occurrence in food and diet and the toxicological implications. Food Addit Contam 1990;7:717-68.

22 Sanderson MJ, Schorah CJ. Measurement of ascorbic acid and dehydroascorbic acid in gastric juice by high pressure liquid chromatography. Biomed Chromatogr 1987;2:197-202.

23 Moriya A, Grant J, Williams C, et al. In vitro studies indicate that acid catalysed generation of $\mathrm{N}$-nitrosocompounds from dietary nitrate will be maximal at the gastroesophageal junction and cardia. Scand J Gastroenterol 2002;37:253-61.

24 Varley H. Practical clinical biochemistry, 3rd Edn. London: William Heinemann, 1963:636-7.

25 Mowat C, Carswell A, Wirz A, et al. Omeprazole and dietary nitrate independently affect levels of vitamin $\mathrm{C}$ and nitrite in gastric juice. Gastroenterology 1999;116:813-22.

26 Dykhuizen RS, Masson J, McKnight G, et al. Plasma nitrate concentration in ineffective gastroenteritis and inflammatory bowel disease. Gut 1996;39:393-5.

27 Mowat C, Williams C, Gillen D, et al. Omeprazole, Helicobacter pylori status, and alterations in the intragastric milieu facilitating bacterial $\mathrm{N}$-nitrosation. Gastroenterology 2000;1 19:339-47.

28 Dixon J, Strugala V, Griffin SM, et al. Esophageal mucin: an adherent mucus gel barrier is absent in the normal esophagus but present in columnar-lined Barrett's esophagus. Am J Gastroenterol 2001 ;96:2575-83.

29 lijima K, Fyfe V, McColl KEL. Studies of nitric oxide generation from salivary nitrite in human gastric juice. Scand J Gastroenterol 2003;38:246-52.

30 Licht WR, Tannenbaum SR, Deen WM. Use of ascorbic acid to inhibit nitrosation: kinetic and mass transfer considerations for an in vitro system. Carcinogenesis 1988;9:365-72.

31 Avidan B, Sonnenberg A, Schnell TG, et al. Hiatal hernia and acid reflux frequency predict presence and length of Barrett's esophagus. Dig Dis Sci 2002:47:256-64.

32 lascone C, DeMeester TM, Little AG, et al. Barrett's esophagus. Functional assessment, proposed pathogenesis, and surgical therapy. Arch Surg 1983; 1 18:543-9. 
33 Gillen P, Keeling P, Byrne PJ, et al. Barrett's esophagus: $\mathrm{pH}$ profile. Br J Surg 1987;74:774-6.

34 Champion G, Richter JE, Vaezi MF, et al. Duodenogastro-esophageal reflux: Relationship to $\mathrm{pH}$ and importance in Barrett's esophagus. Gastroenterology 1994; 107:747-54.

35 Singh P, Taylor RH, Colin-Jones DG. Esophageal motor dysfunction and acid exposure in reflux esophagitis are more severe if Barrett's metaplasia is present. Am J Gastroenterol 1994;89:349-56.

36 Iwakiri K, Sugiura T, Hayashi Y, et al. Esophageal motility in Japanese patients with Barrett's esophagus. J Gastroenterol 2003;38: 1036-41.

37 Rakic S, Stein JH, DeMeester TR, et al. Role of esophageal body function in gastroesophageal reflux disease: Implications for surgical management. J Am Coll Surg 1997; 185:380-7.

38 Burnett T, Pung A, Bertram JS, et al. The role of nitric oxide in neoplastic transformation of $\mathrm{C} 3 \mathrm{H} 10 \mathrm{Tl} / 2$ embryonic fibroblasts. Carcinogenesis 1995:21:1989-95.

39 Spek EJ, Wright TL, Stitt MS, et al. Recombinational repair is critical for survival of Escherichia coli exposed to nitric oxide. J Bacteriol 2001;183:131-8.

40 Zhuang JC, Wright T, deRojas-Walker T, et al. Nitric oxide-induced mutations in the HPRT gene of human lymphoblastoid TK6 cells and in Salmonella typhimurium. Environ Mol Mutagen 2000;35:39-47.

41 Laval F, Wink DA, Laval J. A discussion of mechanisms of NO genotoxicity: implication of inhibition of DNA repair proteins. Rev Physiol Biochem Pharmacol 1997;131:175-91.
42 Mirvish SS, Pelfrene AF, Garcia H, et al. Effect of sodium ascorbate on tumor induction in rats treated with morpholine and sodium nitrite, and with nitrosomorpholine. Cancer Lett 1976;2:101-8.

43 Ohsawa K-I, Nakagawa S-Y, Kimura M, et al. Detection of in vivo genotoxicity of endogenously formed $\mathrm{N}$-nitroso compounds and suppression by ascorbic acid, teas and fruit juices. Mutat Res 2003;539:65-76.

44 Pera M, Cardesa A, Bombi JA, et al. Influence of esophagojejunostomy on the induction of adenocarcinoma of the distal esophagus in Sprague-Dawley rats by subcutaneous injection of 2,6-dimethylnitrosomorpholine. Cancer Res 1989:49:6803-8.

45 Attwood SEA, Smyrk TC, DeMeester TR, et al. Duodenoesophageal reflux and the development of esophageal adeonocarcinoma in rats. Surgery 1992;111:504-509.

46 Xu X, LoCicero J, Macri E, et al. Barrett's esophagus and associated adenocarcinoma in a mouse surgical model. J Surg Res 2000:88:120-4.

47 Ouatu-Lascar R, Fitzgerald RC, Triadfilopoulos G. Differentiation and proliferation in Barrett's esophagus and the effects of acid suppression. Gastroenterology 1999;117:327-35.

48 Fitzgerald RC, Omary MB, Triadafilopoulos G. Dynamic effects of acid on Barrett's esophagus. An ex vivo proliferation and differentiation model. J Clin Invest 1996;98:2120-8.

49 Kaur BS, Triadafilopoulos G. Acid- and bile-induced $\mathrm{PGE}_{2}$ release and hyperproliferation in Barrett's esophagus are COX-2 and PKC-E dependent. Am J Physiol Gastrointest Liver Physiol 2002;283:G327-34.

50 Souza RF, Shewmake K, Terada LS, et al. Acid exposure activates the mitogen-activated protein kinase pathways in Barrett's esophagus. Gastroenterology 2002; 122:299-307.

\section{EDITOR'S QUIZ: GI SNAPSHOT}

\section{Abdominal pain in a patient with an oesophageal stent}

\section{Clinical presentation}

A 90 year old female teetotal exsmoker was admitted with a two day history of central abdominal pain. She was nauseated and had not opened her bowels for the past two days. She had a history of laparoscopic cholecystectomy and oesophageal stent insertion for a benign oesophageal stricture secondary to acid reflux. She was taking fexonidine, valdecoxib, ferrous sulphate, cocodamol, and lansoprazole.

On examination, vital signs were normal. She had a tender and distended abdomen. Bowel sounds were present. She had a mildly raised urea level of $10.4 \mathrm{mmol} / \mathrm{l}$. Her renal and liver biochemistry profiles were otherwise unremarkable. Full blood count was normal. Figure 1 shows her abdominal radiograph on admission.

\section{Question}

How would you manage the patient?

See page 1584 for answer

This case is submitted by:

K T Tan, N Borley, R Hopkins Cheltenham General Hospital, Cheltenham, UK

Correspondence to: Dr K T Tan, Department of Radiology, Bristol Royal Infirmary, Bristol BS2 8HW, UK; K.T.Tan@bristol.ac.uk

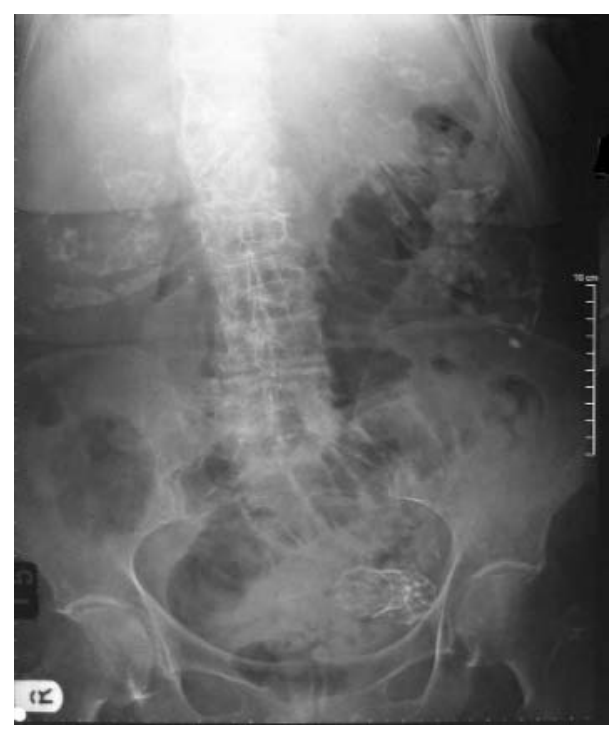

Figure 1 Abdominal radiograph on admission. 